\title{
The Coexistence of Humans and Companion Animals in the City Parks of Xanthi: The Views of the Citizens
}

\author{
Paraskevi Karanikola, ${ }^{1}$ Evangelos Manolas, ${ }^{1}$ \\ Stilianos Tampakis, ${ }^{1}$ and Thomas Panagopoulos ${ }^{2}$ \\ ${ }^{1}$ Department of Forestry and Management of the Environment and Natural Resources, Democritus University of Thrace, \\ 193 Pantazidou str., 68200 Orestiada, Greece \\ ${ }^{2}$ Research Centre for Spatial and Organizational Dynamics (CIEO), University of the Algarve, Gambelas Campus, 8000 Faro, Portugal
}

Correspondence should be addressed to Thomas Panagopoulos, tpanago@ualg.pt

Received 27 July 2012; Revised 19 October 2012; Accepted 19 November 2012

Academic Editor: Heejun Chang

Copyright (C) 2012 Paraskevi Karanikola et al. This is an open access article distributed under the Creative Commons Attribution License, which permits unrestricted use, distribution, and reproduction in any medium, provided the original work is properly cited.

Companion animals are very important to people of big cities. In Greece the families which own those animals take them for a walk in the parks and streets of their town but not always with care to not disturb other citizens. Laws and regulations for companion and stray animals are not respected in Greece, although as a result of the Athens Olympics in 2004 the Greek government started to provide funds for the collection, care, and sterilization of stray animals. This paper is a first attempt to record, through the aid of a structured questionnaire, the view of the citizens of the city of Xanthi in northern Greece regarding companion animals and what they do when animals become old. The paper also examines the extent to which the existence of stray and companion animals in parks disturbs the people who visit green areas looking for a place to get a rest or play on the grass. The majority preferred that stray animals are collected off the streets, recorded, treated from parasites, vaccinated, and sterilized and after that are available for adoption or are returned to the area they were found at.

\section{Introduction}

In all societies people coexist with animals. The interaction of humans with animals takes place in various forms from parasitism and rapacity to companionship [1]. Recent human history may be seen as a gradual displacement from life in nature to life in cities. Man is a species which evolved from the natural environment and, therefore, finds it difficult to live without some contact with nature [2]. The urban environment is a part of the global ecological network [3] where the combination of diverse human actions and natural forces will continue to shape urban green areas as an everyday environment for people.

Nevertheless, in our movement from the natural environment to the cities we were followed by companion animals, which just like us also use the urban green. Generally, Greek cities do not have the green they should have. In Greece, only $2.8 \mathrm{~m}^{2}$ of green space is available to each individual, whereas in Western Europe $20 \mathrm{~m}^{2} /$ person is available [4]. The inhabitants of Greek cities are called to share with companion animals this small urban space of green.

Companion animals are very important to people who own them. The relationship of people with companion animals is often so strong that in cases of physical disasters their owners refuse to abandon their house without their pet [5]. Research has been carried out on the physical and mental benefits humans have from their companionship with animals [6]. Such benefits include the prevention and recovery as well as the ability of some animals to detect particular diseases in humans [7]. For heart-artery problems the presence of a pet may be more beneficial than the presence of a friend or husband/wife. Many research papers have shown that companion animals improve the 
psychological well-being not only of their owners but also of the people who accompany them [8]. This is particularly true for old people [9].

The way we treat animals shows how we view people and indeed how we treat people [6]. In many developed countries such as the United States or the United Kingdom, the state provides services for collecting, taking care of, feeding, and accommodating abandoned animals. Of course this is an additional cost for the governments of these countries. Regarding poorer countries such as Greece the provision of funds by the state for such purposes is limited and for this reason the number of stray animals in city parks and streets is increasing. Even if the abandonment of an animal is forbidden by the international legislation [10], which is also incorporated in the Greek legislation, (law 1197/1981, law 2017/1992, and law 3170/2003), such an act is the usual practice in Greek cities.

The stimulus for writing this paper was the need for the coexistence of humans and animals in the parks of Xanthi. The aim of the paper aspires to be a first attempt to record the views of the citizens of Xanthi with regard to animals, pets, or stray animals, which are visiting or roaming the parks of the city. What is the relationship between humans and animals and how can this relationship improve? What happens when the owner of an animal ceases to want this animal in his house and how do the citizens perceive the management of stray animals?

\section{Research Methodology}

The research was carried out with an application of a face to face structured questionnaire. Since in Greece and in neighboring countries there are no relevant papers on the subject of this paper this questionnaire was constructed with questions taken from the daily press (newspapers) of the country. The research area of this paper was the city of Xanthi. The sampling method used was simple random sampling [11, 12].

The "population" under investigation was the total households in the city of Xanthi. The applied sampling frame was the catalogue of electricity consumers. Data were collected in 2007. The population's proportion which is also the objective estimation of the real population proportion $p$ as well as the estimation of the typical error of the population $s_{p}$, without the correction of the finite population (because the size of the sample is small), was carried out through the use of the formulas of simple random sampling. In order to calculate the size of the sample we carried out presampling, with the size of the sample being 50 individuals. The size of the sample was estimated according to the formulas of simple random sampling (where $t=1.96$ and $e=5 \%$ ) [13]. The total number of interviews was 385 .

In order to test whether the three pairs of variables "reaction regarding stray animals and behavior of stray animals," "reaction regarding pets and collection of excrements", and "reaction regarding pets and ownership of pets" are independent between themselves, the test of independence was used. The criterion used was $\chi^{2}[14-18]$. However, neither the measurement of intensity nor the specification of the nature of the (probable) relation of the variables can result from the statistical $\chi^{2}$. For this reason, a series of contingency measures have been created. In categorical imperatives only the intensity is meaningful and the measures which rely on the statistical $\chi^{2}$ are the phi coefficient, Gramer's $V$ coefficient and the contingency coefficient. The phi coefficient also examines the direction between the variables.

Regarding the research on how stray animals are created it was asked to state the personal experiences of the participants. More specifically it was asked what the owners of companion animals do when they do not want or they cannot keep any more their animals with them; what they do if they do not know someone to give the animals to.

\section{Results}

3.1. Stray and Companion Animals in the Parks of the Xanthi City. In the city of Xanthi as well as in other big cities of Greece we can see stray animals roaming in the parks and also companion animals, especially dogs with their owners, making their daily walk. During the interviews, the citizens initially were asked if there were stray animals in the parks they visited. $94.5 \%\left(s_{p}=0.0116\right)$ replied positively, $4.9 \%$ $\left(s_{p}=0.0111\right)$ replied negatively, and $0.5 \%\left(s_{p}=0.0037\right)$ did not answer the question. In the question whether there are animals which are accompanied by their owners $83.1 \%$ $\left(s_{p}=0.0191\right)$ replied positively, $12.2 \%\left(s_{p}=0.0167\right)$ replied negatively, and $4.7 \%\left(s_{p}=0.0108\right)$ did not answer the question. On the first thought, one could claim that stray animals are more than the pets. However, this is probably not true because these animals live and move in their own areas mainly in public areas and interact with people who offer them little food and sometimes love. It is reasonable, therefore, that these animals are seen by the citizens on a daily basis, in contrast to pets which are taken to the park by their owners sometimes during the day or night.

The existence of stray animals in the parks and public areas of the city seems to bother more than half of the citizens $\left(67.8 \%, s_{p}=0.0238\right)$, while $20.5 \%\left(s_{p}=0.0206\right)$ say that they are indifferent to their existence and $6 \%$ say that they are entertained by the existence of stray animals. Indeed, $36.4 \%\left(s_{p}=0.0245\right)$ characterize the behaviour of stray animals as hostile, $53.8 \%\left(s_{p}=0.0254\right)$ as neutral, and $9.4 \%$ $\left(s_{p}=0.0149\right)$ as friendly.

After grouping the answers to create a $2 \times 2$ table, the test of independence to the two variables mentioned above was applied (Table 1). Through the test of independence the null hypothesis was checked: Ho means there is no difference between the variables.

The value of Pearson's $\chi^{2}$ was 29.943 with a degree of freedom 1 and the correlation was statistically significant with a level of significance $\alpha<0.005$ which showed a strong correlation between the variables "reaction regarding stray animals" and "behavior of stray animals."

Regarding the relation between the variables the same conclusion with Yates' continuity correction (in $2 \times 2$ tables) was reached. The value $\chi^{2}$ with continuity correction was 
TABLE 1: Cross-tabulation of variables "reaction regarding stray animals" and "behaviour of stray animals."

\begin{tabular}{lcccc}
\hline & & \multicolumn{2}{c}{ Behaviour of stray animals } & Total \\
\multicolumn{2}{c}{ Reaction regarding stray animals } & Hostile & Neutral or friendly & \\
\hline \multirow{2}{*}{ It bothers you } & Observed count & 119 & 140 & 259 \\
& Expected count & 94 & 164 & 259 \\
& Residual & 24 & -24 & 123 \\
It entertains you, it & Observed count & 21 & 102 & 123 \\
makes you indifferent & Expected count & 45 & 77 & 382 \\
or something else & Residual & -24 & 24 & 382 \\
\hline \multirow{2}{*}{ Total } & Observed count & 140 & 242 & 242 \\
\end{tabular}

28.713 with a degree of freedom 1 and the correlation was statistically significant with a level of significance $\alpha<0.005$. The value $\chi^{2}$ of the likelihood ratio which was 32.217 and the correlation are statistically significant.

The citizens who were bothered by stray animals in the parks think that the behavior of those animals as hostile, which was in contrast to those citizens who think of the behavior of these animals as entertaining or indifferent or friendly. The above can also be extracted from the coefficient phi which is equal to 0.28 (positive) and the correlation between the variables is statistically significant. Gramer's $V$ coefficient also has the same value while the coefficient of contingency is 0.270 and the correlation between the variables is statistically significant.

The attitudes of citizens towards the existence of companion animals in parks and public city areas vary. The majority of the citizens $\left(53.5 \%, s_{p}=0.0255\right)$ say that they are indifferent to the existence of these animals, while $23.6 \%$ $\left(s_{p}=0.0255\right)$ declare that the existence of such animals bothers them and $20 \%\left(s_{p}=0.0204\right)$ say that it entertains them.

Taking the animals out to the park was important so that they can satisfy their needs. Without doubt, according to article 2, paragraph 1 of Law 3170/2003 "Pets, stray animals and other regulations" (Newspaper of the Greek Government 191/29-7-2003, Issue A), it is the obligation of the owners of pets to take care of the immediate cleaning of the environment regarding the excrements of their dogs. Unfortunately, $91.4 \%\left(s_{p}=0.0143\right)$ of the citizens say that the pet owners never collect the excrements of their dogs, $7 \%\left(s_{p}=0.0130\right)$ say that the owners usually do, and $1 \%$ $\left(s_{p}=0.052\right)$ say that they never do.

The value of Pearson's $\chi^{2}$ was 13.593 and the correlation was statistically significant showing a strong association between the variables "reaction regarding pets" and "collection of excrements" (Table 2). The same conclusion was extracted from the value of $\chi^{2}$ with continuity correction 11.916 and the value $\chi^{2}$ of the likelihood ratio 11.253 which were statistically significant.

The citizens who are bothered or are indifferent or something else by the existence of animals which are accompanied think that their owners never collect the excrements of their animals. This is in contrast to those who declare that the existence of animals which are accompanied entertains them

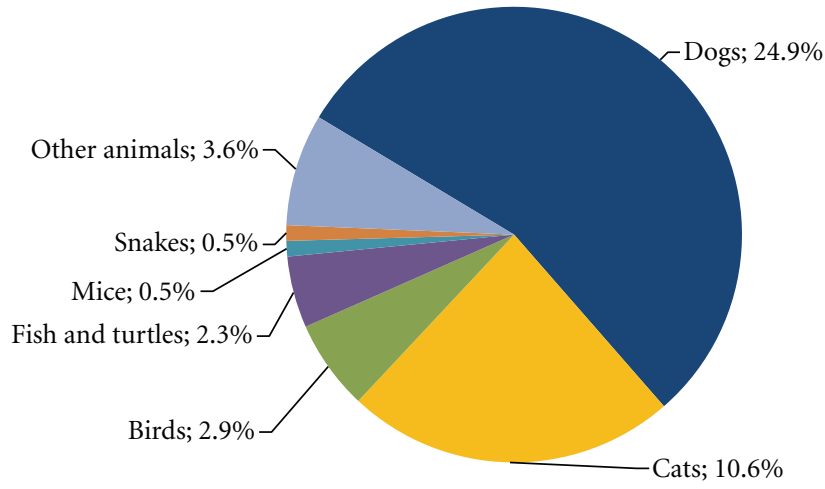

Figure 1: The most preferred pets of the citizens of Xanthi.

and who declare that the owners, always or usually, collect the excrements of their animals. Also, the same conclusion was given by the phi coefficient which was equal to 0.188 (negative) and the correlation between the variables was statistically significant $(\alpha<0.005)$. Gramer's V coefficient also had the same value while the coefficient of contingency was 0.785 and the correlation between the variables was statistically significant $(\alpha<0.005)$.

3.2. Behavior of Citizens Who Own Companion Animals. With regard to the question on whether their family owns a pet, $34.8 \%\left(s_{p}=0.0243\right)$ of the citizens replied positively, $62.1 \%\left(s_{p}=0.0248\right)$ replied negatively while $3.1 \%\left(s_{p}=\right.$ $0.0089)$ did not answer the question. The dogs were the most preferred pets $\left(s_{p}=0.0221\right)$ followed by cats $\left(s_{p}=0.0157\right)$, songbirds $\left(s_{p}=0.0085\right)$, fish and turtles $\left(s_{p}=0.0077\right)$, mice, and a snakes $\left(s_{p}=0.0037\right)$, while other animals were declared from the $3.6 \%\left(s_{p}=0.0096\right)$ of the citizens of Xanthi (Figure 1). Many pet owners have more than one dog or cat (Figure 2); nevertheless, with regard to the question whether they have put a microchip on their dog only $4.9 \%$ $\left(s_{p}=0.0111\right)$ replied positively.

After grouping the answers, the test of independence to the variables "animals which are accompanied" and "ownership of pets" (Table 3) was applied. The value of Pearson's $\chi^{2}$ was 21.473 with a degree of freedom 1 and the correlation was statistically significant with level of 
TABLE 2: Cross-tabulation of variables "reaction regarding pets" and "collection of excrements."

\begin{tabular}{|c|c|c|c|c|}
\hline & & \multicolumn{2}{|c|}{ Collection of excrements } & Total \\
\hline \multicolumn{2}{|c|}{ Reaction regarding pets } & Always/usually & Never & \\
\hline \multirow{3}{*}{$\begin{array}{l}\text { It bothers you or } \\
\text { makes you indifferent } \\
\text { or something else }\end{array}$} & Observed count & 17 & 290 & 307 \\
\hline & Expected count & 24 & 282 & 307 \\
\hline & Residual & -7 & 7 & \\
\hline \multirow{3}{*}{ It entertains you } & Observed count & 14 & 62 & 76 \\
\hline & Expected count & 6.2 & 69 & 76 \\
\hline & Residual & 7 & -7 & \\
\hline \multirow{2}{*}{ Total } & Observed count & 31 & 352 & 383 \\
\hline & Expected count & 31 & 352 & 383 \\
\hline
\end{tabular}

TABLE 3: Cross tabulation of the variables "reaction regarding pets" and "pet ownership."

\begin{tabular}{|c|c|c|c|c|}
\hline \multirow{2}{*}{\multicolumn{2}{|c|}{ Reaction regarding pets }} & \multicolumn{2}{|c|}{ Pet ownership } & Total \\
\hline & & Yes & No & \\
\hline \multirow{3}{*}{$\begin{array}{l}\text { It bothers you or } \\
\text { makes you indifferent } \\
\text { or something else }\end{array}$} & Observed count & 89 & 208 & 297 \\
\hline & Expected count & 106 & 190 & 297 \\
\hline & Residual & -17 & 17 & \\
\hline \multirow{3}{*}{ It entertains you } & Observed count & 44 & 31 & 75 \\
\hline & Expected count & 26 & 48 & 75 \\
\hline & Residual & 17 & -17 & \\
\hline \multirow{2}{*}{ Total } & Observed count & 133 & 239 & 372 \\
\hline & Expected count & 133 & 239 & 372 \\
\hline
\end{tabular}

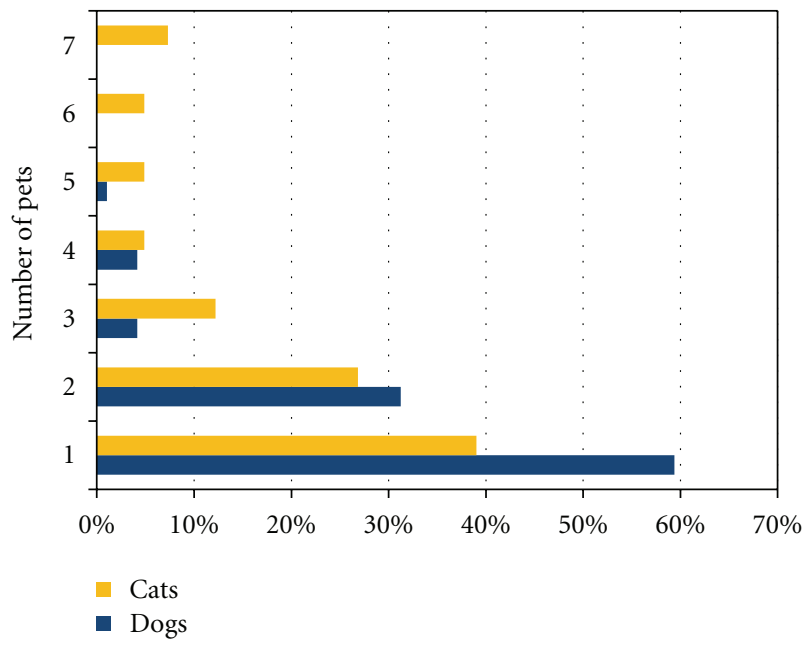

Figure 2: Percentage of pet owners with one or more dog or cat.

significance $\alpha<0.005$. This shows that there is a strong correlation between the variables "reaction regarding pets" and "ownership of pets." The same conclusion can be extracted from the value $\chi^{2}$ with continuity correction 20.241 and the value $\chi^{2}$ of the likelihood ratio which was 20.683 both with the correlation being statistically significant.

Also, it was observed that the citizens who do not own pets are bothered or are indifferent or something else by the existence of accompanied animals, in contrast to those who own pets that are entertained in the existence of them in the city open spaces. In addition, the same conclusion was extracted by the phi coefficient which was equal to -0.240 (negative) with the correlation between the variables being statistically significant $(\alpha<0.005)$. Gramer's $V$ coefficient also had the same value, while the coefficient of contingency was 0.234 and the correlation between the variables is statistically significant $(\alpha<0.005)$.

3.3. Reasons for the Increase in the Number of Stray Animals. The majority of the participants $48.3 \%\left(s_{p}=0.0255\right)$ stated that they abandon their pets in a village or mountain and $35.3 \%\left(s_{p}=0.024\right)$ say that they abandon them somewhere in the city. Only $5.5 \%\left(s_{p}=0.011\right)$ said that they give them to shelters and $2.9 \%\left(s_{p}=0.008\right)$ opted to lead them to euthanasia. Other participants say that they do something else $3.6 \%\left(s_{p}=0.009\right)$, while $4.4 \%\left(s_{p}=0.010\right)$ did not answer the question.

The above attitudes are encouraged by the absence of identification on the animals, and also by the difficulty of the citizens to accept euthanasia for their companion animals. Thus, the following dilemma was given to those who participated in this research: "Although some think that the use of euthanasia, via an ejection by a vet, is a sin, nevertheless, the abandoned animals are usually led to tortuous death from starvation or thirst. If you were in the difficult position of being unable to host your pet, which of the two would you choose?" 
The majority of the participants $51.7 \%\left(s_{p}=0.0255\right)$ supported euthanasia, 37.7\% $\left(s_{p}=0.0247\right)$ supported abandonment, while $10.6 \%\left(s_{p}=0.0157\right)$ did not answer the question. Since in both cases the animals will be led to death, the fastest and most painless way was chosen as the best.

Regarding the variables "euthanasia or abandonment of the animals when the people cannot take care of them" and "ownership of companion animals" the test of independence was applied and the results are presented in Table 4. The value of Pearson's $\chi^{2}$ was 8.007 showing a strong and statistically significant correlation at the level of significance $\alpha<0.005$. The value $\chi^{2}$ with continuity correction was 7.365 and the $\chi^{2}$ of the likelihood ratio was 7.984 showing statistically significant correlation.

The citizens whose family do not have companion animals are in favor of euthanasia as opposed to those who own companion animals and who support the abandonment of animals when their owners cannot take care of them. We were also led to the above conclusion by the phi coefficient which was equal to -0.153 (negative) and the correlation between the variables was statistically significant $(\alpha<0.005)$. Gramer's V coefficient also takes the same value, while the coefficient of contingency was 0.152 and the correlation between the variables was statistically significant $(\alpha<0.005)$.

However, the view of the citizens with regard to two proposals scenarios on the management of stray animals was more interesting. According to the first proposal scenario, the stray animals are collected from the streets and after a brief period of being hosted in shelters will die via euthanasia unless they are adopted by someone. In the second proposalscenario, the stray animals are collected from the streets and after they are recorded, have parasites removed from them, vaccinated, and sterilized, if they are not adopted by someone, they are returned to the area they were found at. The majority of the Xanthi citizens $52.2 \%\left(s_{p}=0.025\right)$ choose the second scenario, which, it should be noted, was already applied in Athens during the 2004 Olympic games and has become known as Athens 2004. In reality, Athens 2004 was an application of article 7, paragraph 4 of Law $3170 / 2003$. The first scenario was accepted by $35.8 \%\left(s_{p}=\right.$ 0.024) of the citizens and for many other countries it is the most usual method for the management of stray animals. This question was not answered by $11.9 \%$ of the citizens $\left(s_{p}=0.016\right)$.

Regarding the variables "scenarios of management of stray animals" and "ownership of companion animals" the test of independence was applied (Table 5). The value of Pearson's $\chi^{2}$ was 13.590 with a degree of freedom 1 while the correlation was statistically significant with the level of significance being $\alpha<0.005$. There was a strong correlation between the variables "scenarios of management of stray animals" and "ownership of companion animals." The same was a conclusion by the value $\chi^{2}$ of the continuity correction and the value $\chi^{2}$ of the likelihood ratio.

The citizens whose family do not have companion animals were in favor of euthanasia as opposed to those who own companion animals and who prefer the return of stray animals in the area they were found at. We can draw the same conclusion by the phi coefficient which was -0.201 (negative) and the correlation between the variables was statistically significant $(\alpha<0.005)$. Gramer's $V$ coefficient also takes the same value, while the coefficient of contingency was 0.197 and the correlation between the variables was statistically significant $(\alpha<0.005)$.

In other countries that are considered as more developed countries such as the US, UK, and Australia they say that the existence of stray animals in a city is an indication of a low cultural level. However, if we take into account that as a society the Greek citizens accept that some stray animals should share the same space with us, then this shows civilization and kindness. Consequently, during the Olympic Games of Athens the stray animals were collected from the streets and were returned to the streets after the termination of the Athens Olympics.

Finally, the inhabitants of Xanthi were asked to assess the organizations which promote the idea of being friendly or/and caring about animals in a scale from 1 to 10 (1 being insignificant contribution and 10 very significant contribution). It is not accidental that societies for the protection of animals received the highest rating (mean $=$ 6.27 , with standard deviation $=3.03$ ) with the ones coming next the veterinarian services $($ mean $=4.51$, s.d. $=2.84)$. The means of mass communication is followed with mean that equals 3.94 (s.d. $=2.64$ ) and finally the local government mean that equals 3.14 (s.d. $=2.41)$.

3.4. Demographic Attributes. The demographic attributes of the people who participated in the research are given in Table 6. The majority was married, without children, finished the upper school education, and employed in private companies. Regarding the combination of the variables gender, age, education, and the questions of the questionnaire we cannot reject the null hypothesis (Ho means there is no difference between the variables) and so we are uncertain as to whether the attributes are independent or not.

\section{Discussion and Conclusions}

The majority of the citizens of Xanthi (94.5\%) notices the existence of stray animals in the parks of their city, while a lower percentage $(83.1 \%)$ notices the presence of animals which are accompanied by their owners. This may be explained by the fact that pets are taken out during certain hours of the day or night, while stray animals can be found in the streets any time of the day or night [19]. Consequently, a large percentage of the participants $(67.8 \%)$ declare that they are bothered by the existence of stray animals in the public areas of the city.

Even if the majority of the citizens $(53.8 \%)$ characterizes the behaviour of stray animals as neutral, a large part of them (36.4\%) characterize it as hostile. Indeed, through the aid of the test of independence, it was observed that the citizens who are bothered by the existence of stray animals regard the behavior of these animals as hostile, in contrast to those who are entertained or are indifferent or something else by the behaviour of these animals. The latter think of the behavior of stray animals as neutral or friendly. According to Wagstaff 
TABLE 4: Cross tabulation of the variables "euthanasia or abandonment of companion animals" and "pet ownership."

\begin{tabular}{|c|c|c|c|c|}
\hline & & \multicolumn{2}{|c|}{ Pet ownership } & Total \\
\hline \multicolumn{2}{|c|}{ Euthanasia or abandonment of companion animals? } & Yes & No & \\
\hline \multirow{3}{*}{ Euthanasia } & Observed count & 55 & 142 & 197 \\
\hline & Expected count & 67 & 129 & 197 \\
\hline & Residual & -12 & 12 & \\
\hline \multirow{3}{*}{ Abandonment } & Observed count & 61 & 82 & 143 \\
\hline & Expected count & 48 & 94 & 143 \\
\hline & Residual & 12 & -12 & \\
\hline \multirow{2}{*}{ Total } & Observed count & 116 & 224 & 340 \\
\hline & Expected count & 116 & 224 & 340 \\
\hline
\end{tabular}

TABLE 5: Cross tabulation of the variables "scenarios of management of stray animals" and "ownership of companion animals."

\begin{tabular}{|c|c|c|c|c|}
\hline & & \multicolumn{2}{|c|}{ Ownership of pets } & Total \\
\hline \multicolumn{2}{|c|}{ Scenarios of management of stray animals } & Yes & No & \\
\hline \multirow{3}{*}{ Euthanasia } & Observed count & 34 & 103 & 137 \\
\hline & Expected count & 50 & 87 & 137 \\
\hline & Residual & -16 & 16 & \\
\hline \multirow{3}{*}{$\begin{array}{l}\text { Returning the animals } \\
\text { to the area they were } \\
\text { found at }\end{array}$} & Observed count & 89 & 111 & 200 \\
\hline & Expected count & 73 & 127 & 200 \\
\hline & Residual & 16 & -16 & \\
\hline \multirow{2}{*}{ Total } & Observed count & 123 & 214 & 337 \\
\hline & Expected count & 123 & 214 & 337 \\
\hline
\end{tabular}

[20], people who were more empathetic to animals were more sympathetic to animal rights and animal welfare issues and were more positive and sympathetic toward human beings. People that scored high on empathy for animals, on concern for animal rights, were less negative toward the society and more tolerant to difference. Women were more empathetic toward the animals, but no other variables showed gender differences.

In contrast, the majority of the citizens (53.5\%) declares that they are indifferent to the existence of pets which are accompanied by their owners, while $23.6 \%$ say that their existence bothers them. The test of independence shows that the citizens who are bothered or are indifferent regarding accompanied animals believe that their owners never collect the excrements of their animals, in contrast to those who are entertained by accompanied animals and who declare that the owners of the animals, always or usually, collect the excrements of their animals.

A quite large percentage of citizens (34.8\%) replied that their family owns some kinds of pet. Indeed, through the aid of the test of independence it was seen that the family of the citizens who are bothered or are indifferent by the existence of accompanied animals does not own pets, in contrast to those who are entertained by the existence of animals and who declare that they own some animals.

The citizens of Xanthi believe that when the animal's owners do not want these animals and do not know anyone to give them to, they abandon them in rural areas $(48.3 \%)$, or in the city $(35.3 \%)$. The above tactics are encouraged by the absence of identification on the animals, since only $4.9 \%$ of the citizens have put a microchip on them, which was one out five owners (20\% of the owners).

It is difficult for the citizens of Xanthi to accept euthanasia for their animals, which confirm previous studies in other countries $[21,22]$. Although the animals which are abandoned are usually led to tortuous death by starvation or thirst, nevertheless, the abandonment of animals as a choice continues to occupy quite a high percentage. Indeed, with the help of the test of independence we see that the citizens whose family does not keep companion animals are in favor of euthanasia as opposed to those who do keep companion animals and support the view that people who cannot take care of companion animals should abandon them.

As a result of this belief, there are many stray animals in Greece because owners feel pity to them and prefer to set them loose than to euthanize them. In other European countries, on the other hand, cruelty involves denying the animal comfortable care, and if the animal is suffering, euthanasia is the desirable response [23].

With regard to proposal scenarios for the management of stray animals, it was concluded that the first scenario was accepted by $35.8 \%$ of the citizens. This scenario says that the animals which are collected from the streets, after a brief period of being hosted in shelters, die via euthanasia unless of course they are adopted by someone. The second proposal scenario was accepted by $52.2 \%$ of the citizens who say that the animals which are collected from the streets, after they are recorded, treated from parasites, vaccinated, and sterilized, 
TABLE 6: Sociodemographic profile of the sample (\%).

\begin{tabular}{lc}
\hline (1) Gender & \\
Male & $49.4 \%\left(s_{p}=0.025\right)$ \\
Female & $50.6 \%\left(s_{p}=0.25\right)$ \\
\hline (2) Age & \\
$18-30$ & $27.8 \%\left(s_{p}=0.022\right)$ \\
$31-40$ & $25.7 \%\left(s_{p}=0.022\right)$ \\
$41-50$ & $24.2 \%\left(s_{p}=0.021\right)$ \\
$>50$ & $18.2 \%\left(s_{p}=0.019\right)$ \\
\hline
\end{tabular}

$\begin{array}{lc}\text { (3) Marital Status } & \\ \text { Unmarried } & 36.1 \%\left(s_{p}=0.024\right) \\ \text { Married } & 51.7 \%\left(s_{p}=0.025\right) \\ \text { Divorced or widowed } & 6.2 \%\left(s_{p}=0.012\right) \\ \text { Did not answer the question } & 6 \%\left(s_{p}=0.012\right)\end{array}$

\begin{tabular}{lc}
\hline (4) Childhood & \\
Without children & $49.9 \%\left(s_{p}=0.025\right)$ \\
One child & $10.4 \%\left(s_{p}=0.015\right)$ \\
Two children & $31.7 \%\left(s_{p}=0.023\right)$ \\
Three children & $4.9 \%\left(s_{p}=0.011\right)$ \\
More than three children & $3.1 \%\left(s_{p}=0.008\right)$ \\
\hline (5) Educational level & \\
Primary School & $7.3 \%\left(s_{p}=0.013\right)$ \\
Lower Secondary School & $8.1 \%\left(s_{p}=0.013\right)$ \\
Technical School & $13.2 \%\left(s_{p}=0.017\right)$ \\
Upper Secondary School & $37.4 \%\left(s_{p}=0.024\right)$ \\
Technological education & $13.2 \%\left(s_{p}=0.017\right)$ \\
University & $14.8 \%\left(s_{p}=0.018\right)$ \\
\hline
\end{tabular}

(6) Profession

\begin{tabular}{lc} 
Private employee & $29.6 \%\left(s_{p}=0.023\right)$ \\
Public servants & $26.5 \%\left(s_{p}=0.022\right)$ \\
Self-employed & $10.4 \%\left(s_{p}=0.015\right)$ \\
Students & $7.8 \%\left(s_{p}=0.013\right)$ \\
Unemployed & $7 \%\left(s_{p}=0.013\right)$ \\
Housewives & $4.9 \%\left(s_{p}=0.011\right)$ \\
Farmers or stock breeders & $4.7 \%\left(s_{p}=0.013\right)$ \\
Pensioners & $3.6 \%\left(s_{p}=0.009\right)$ \\
Did not answer the question & $4.9 \%\left(s_{p}=0.011\right)$ \\
\hline$)$ Annual income & \\
$<5,000$ euro & $7.5 \%\left(s_{p}=0.013\right)$ \\
$5,000-10,000$ euro & $6.5 \%\left(s_{p}=0.012\right)$ \\
$10,001-15,000$ euro & $13 \%\left(s_{p}=0.017\right)$ \\
$15,001-20,000$ euro & $18.4 \%\left(s_{p}=0.019\right)$ \\
$>20,000$ euro & $5.7 \%\left(s_{p}=0.011\right)$ \\
No answer & $48.8 \%\left(s_{p}=0.025\right)$ \\
\hline
\end{tabular}

are available for adoption for a short period or they are returned to the area they were found. Indeed with the help of the test of independence we see that citizens whose family do not have companion animals are in favor of euthanasia as opposed to those who do keep companion animals and support the return of stray animals to the area they were found at.
Indeed, the latter solution was applied also during the Athens Olympics of 2004. This system is applicable and enjoys wide support and, therefore, its application in the long term will alleviate the problem of stray animals. This system will also help the citizens to accept stray animals since they will realize that they do not constitute a serious danger for them and their children.

According to previous studies [24,25], pets and animals are important for public pedagogy and children's environmental education; meanwhile only $49.9 \%$ of the study sample dwells had children and children did not take part in the present study. Assessing the organizations which promote the idea of being friendly and caring about animals, the finding of the present study are in line with the findings of previous studies [26-29], with the highest rating given to societies for the protection of animals with the next ones being the veterinarian services, the mass media of communication, and finally the local government.

While it is important to benchmark attitudes toward the treatment of animals within a community sample, the current study has several limitations. The results of other studies have suggested a range of demographic and personality variables that may affect attitudes toward the treatment of non human species. Further research using the Attitude to Animals Scale (AAS), developed initially by Herzog et al. [30], may be used as a quantitative measure of attitudes toward the treatment of non human species.

\section{References}

[1] T. Ingold, What Is an Animal? Cambridge University Press, Cambridge, UK, 1994.

[2] R. W. Miller, Urban Forestry, Planning and Managing Urban Greenspaces, Prentice Hall, Englewood Cliffs, NJ, USA, 2nd edition, 1997.

[3] J. F. Dwyer, D. J. Nowak, and M. H. Noble, "Sustaining urban forests," Journal of Arboriculture, vol. 29, no. 1, pp. 49-55, 2003.

[4] A. Hatzistathis, T. Zagas, D. Trakolis, P. Ganatsas, and G. Malamidis, "Report on the state of art of Greece," in Research and Development in Urban Forestry in Europe, M. Forrest, C. C. Konijendijk, and T. B. Randrup, Eds., pp. 142-156, European Communities, Brussels, Belgium, 1999.

[5] S. E. Heath, P. H. Kass, A. M. Beck, and L. T. Glickman, "Human and pet-related risk factors for household evacuation failure during a natural disaster," American Journal of Epidemiology, vol. 153, no. 7, pp. 659-665, 2001.

[6] S. Knight and H. Herzog, "All creatures great and small: new perspectives on psychology and human-animal interactions," Journal of Social Issues, vol. 65, no. 3, pp. 451-461, 2009.

[7] D. L. Wells, "The effects of animals on human health and wellbeing," Journal of Social Issues, vol. 65, no. 3, pp. 523-543, 2009.

[8] K. Allen, J. Blascovich, and W. B. Mendes, "Cardiovascular reactivity and the presence of pets, friends, and spouses: the truth about cats and dogs," Psychosomatic Medicine, vol. 64, no. 5, pp. 727-739, 2002.

[9] S. Knight and V. Edwards, "In the company of wolves: the physical, social, and psychological benefits of dog ownership," Journal of Aging and Health, vol. 20, no. 4, pp. 437-455, 2008. 
[10] M. P. Chase, "Animal rights: an interdisciplinary, selective bibliography," Law Library Journal, vol. 82, no. 2, pp. 359-391, 1990.

[11] J. Meyerhoff, U. Liebe, and V. Hartje, "Benefits of biodiversity enhancement of nature-oriented silviculture: evidence from two choice experiments in Germany," Journal of Forest Economics, vol. 15, no. 1-2, pp. 37-58, 2009.

[12] D. Hoyos, "The state of the art of environmental valuation with discrete choice experiments," Ecological Economics, vol. 69, no. 8, pp. 1595-1603, 2010.

[13] M. Pagano and K. Gauvreau, Elements of Biostatistics, Ellin Publications, Athens, Greece, 2000.

[14] W. Mendenhall, Introduction to Probability and Statistics, Duxbury Press, Belmont, Calif, USA, 5th edition, 1979.

[15] R. G. D. Steel, J. H. Torrie, and D. A. Dickey, Principles and Procedures of Statistics a Biometrical Approach, WCB/McGrawHill, New York, NY, USA, 1997.

[16] V. G. Makrakis, Data Analysis in Scientific Research Using SPSS, Gutenberg Publications, Athens, Greece, 1997.

[17] C. Gnardellis, Applied Statistics, Papazisis Publications, Athens, Greece, 2003.

[18] D. Howitt and D. Gramer, Statistics With the SPSS 11 For Windows, Prentice Hall, Hemel Hempstead, UK, 2003.

[19] S. Knight, K. Nunkoosing, A. Vrij, and J. Cherryman, "Using grounded theory to examine people's attitudes toward how animals are used," Society and Animals, vol. 11, no. 4, pp. 307327, 2003.

[20] G. Wagstaff, "Attitudes toward animals and human beings," The Journal of Social Psychology, vol. 131, no. 4, pp. 573-575, 1990.

[21] S. A. Balcom, "Legislating a solution to animal shelter euthanasia: a case study of California's controversial SB 1785," Society and Animals, vol. 8, no. 2, pp. 128-150, 2000.

[22] N. Kogure and K. Yamazaki, "Attitudes to animal euthanasia in Japan: a brief review of cultural influences," Anthrozoös, vol. 3, pp. 151-154, 1990.

[23] C. R. Sanders, "Killing with kindness: veterinary euthanasia and the social construction of personhood," Sociological Forum, vol. 10, no. 2, pp. 195-214, 1995.

[24] T. Bjerke, B. P. Kaltenbom, and T. S. Ødegårdstuen, "Animalrelated activities and appreciation of animals among children and adolescents," Anthrozoos, vol. 14, no. 2, pp. 86-94, 2001.

[25] J. Blewitt, "Critical practice and the public pedagogy of environmental and conservation media," Environmental Education Research, vol. 17, pp. 719-734, 2011.

[26] C. J. Soares, "The companion animal in the context of the family system," Marriage and Family Review, vol. 8, pp. 49-62, 1985.

[27] J. H. Church, "In focus: how the media portrays animals," The Animals' Agenda, vol. 16, pp. 24-28, 1996.

[28] G. J. Patronek, "Issues for veterinarians in recognizing and reporting animal neglect and abuse," Society and Animals, vol. 5, no. 3, pp. 267-280, 1997.

[29] A. Arluke, "Coping with euthanasia: a case study of shelter culture.," Journal of the American Veterinary Medical Association, vol. 198, no. 7, pp. 1176-1180, 1991.

[30] H. Herzog, N. Betchart, and R. Pittman, "Sex role identity and attitudes toward animals," Anthrozoös, vol. 4, no. 3, pp. 184192, 1991. 


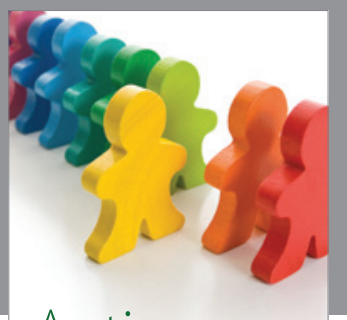

Autism

Research and Treatment
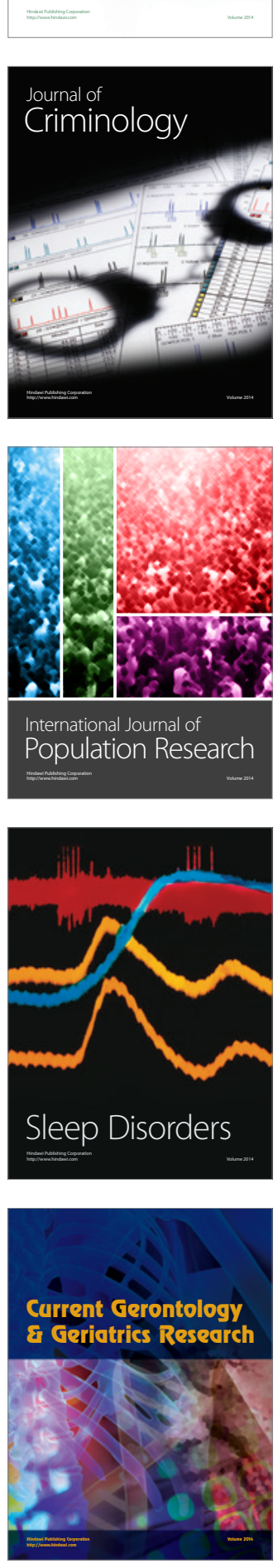
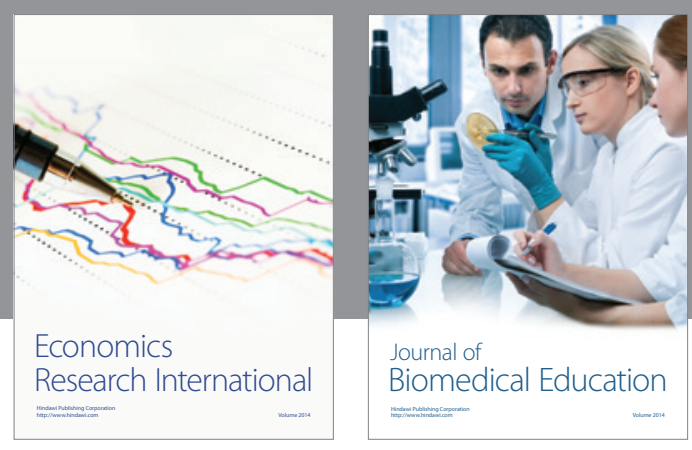

Journal of

Biomedical Education

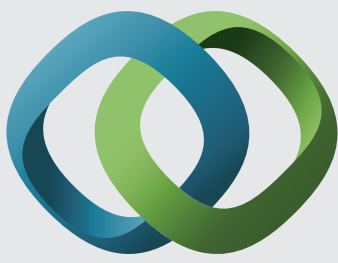

\section{Hindawi}

Submit your manuscripts at

http://www.hindawi.com
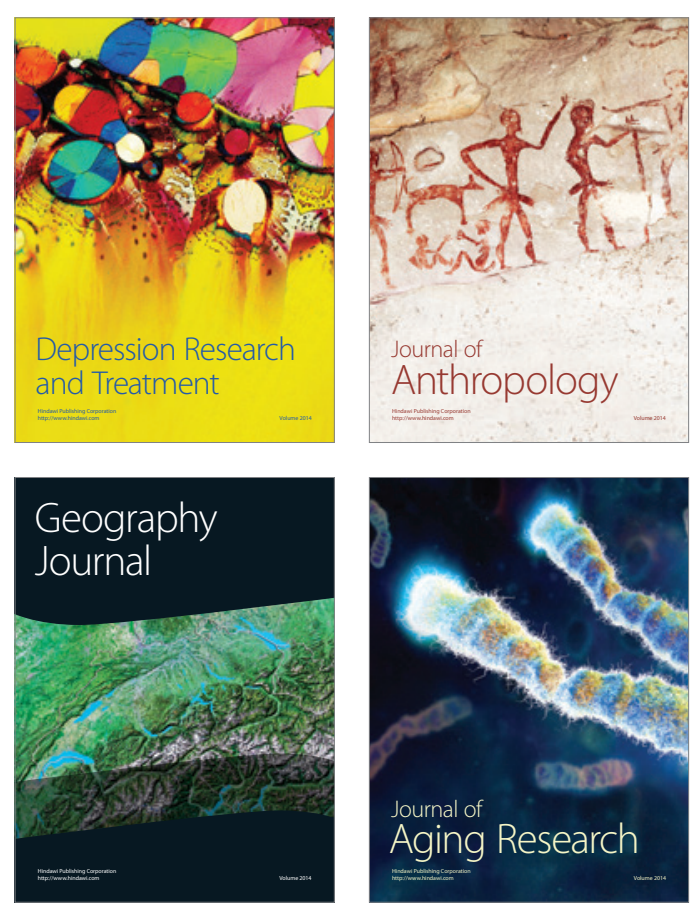

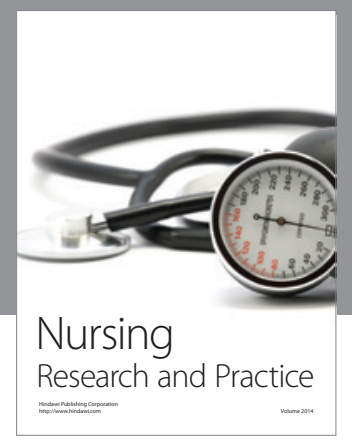

Nursing

Research and Practice

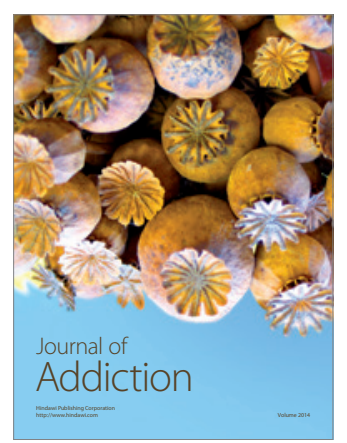

Child Development

Research

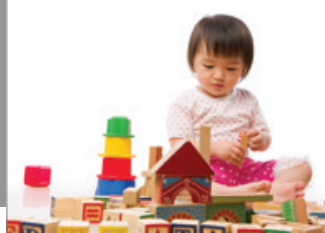

迥
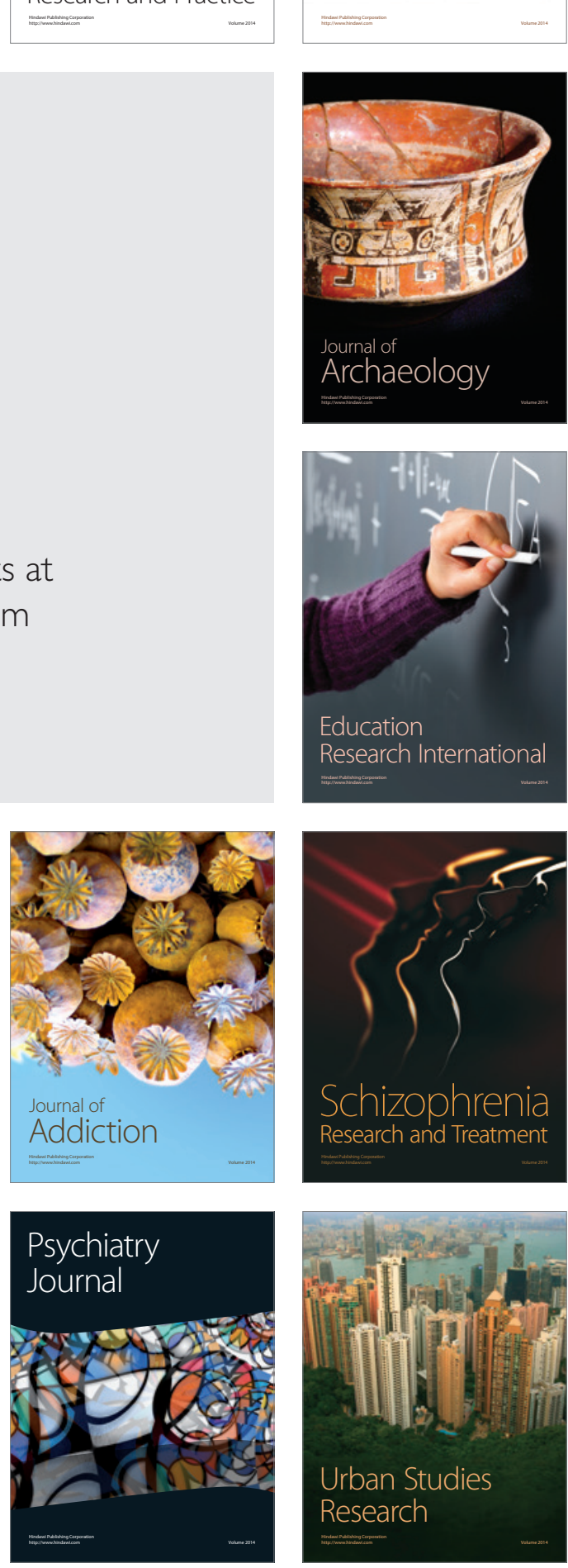